\title{
Exhaled Nitric Oxide and Symptom Severity in Children with Allergic Rhinitis
}

\author{
Jeong Hee Kim ${ }^{1,2^{\star}}$, Ji Sun Park ${ }^{1}$, Seung Hyun Moon ${ }^{1}$, Dae Hyun Lim ${ }^{1,2}$, Seon Yeong Hwang ${ }^{2}$ and Yoon Sung Park ${ }^{2}$ \\ ${ }^{1}$ Department of Pediatrics, Inha University Hospital, Incheon, Korea \\ ${ }^{2}$ Environmental Health Center for Allergic Rhinitis, Inha University Hospital, Incheon, Korea
}

"Corresponding author: Jeong Hee Kim, Department of Pediatrics, Inha University School of Medicine, Inha University Hospital, 27 Inhang-ro, Jung-gu, Incheon 400-711, Korea, Tel: +82-32-890-2843; Fax: +82-32-890-2844; E-mail: kimjhmd@inha.ac.kr

Received date: October 20, 2017; Accepted date: October 23, 2017; Published date: October 30, 2017

Copyright: $\odot 2017 \mathrm{Kim} \mathrm{JH}$, et al. This is an open-access article distributed under the terms of the Creative Commons Attribution License, which permits unrestricted use, distribution, and reproduction in any medium, provided the original author and source are credited.

\begin{abstract}
Objective: There have been few reliable biomarkers to evaluate allergic rhinitis (AR) severity in children. This study aimed to investigate a biomarker for assessing AR severity in children.

Methods: A total of 107 children with AR (80) and non-allergic rhinitis (NAR, 27) were included in this study. The fraction of exhaled nitric oxide (FeNO) was measured and AR severity and duration was graded in patients with AR. We assessed the association between FeNO and the Allergic Rhinitis and its Impact on Asthma (ARIA) classes.

Results: FeNO levels in the AR and NAR groups were $34.7 \pm 22.1$ and $17.0 \pm 13.1 \mathrm{ppb}$, respectively ( $p=0.001)$. FeNO levels were significantly different $(p<0.05)$ in the four ARIA classes: $14.3 \pm 3.7 \mathrm{ppb}$ in the mild intermittent group, $22.7 \pm 4.8 \mathrm{ppb}$ in the mild persistent group, $32.1 \pm 16.1 \mathrm{ppb}$ in the moderate-to-severe intermittent group, and $48.2 \pm 25.2 \mathrm{ppb}$ in the moderate-to-severe persistent group. We collapsed the 4 ARIA classes into 2 groups based on severity or duration. FeNO levels of the mild symptom group and moderate-to-severe symptom group were 18.7 \pm 6.0 and $41.1 \pm 23.0 \mathrm{ppb}$, respectively, which were significantly different $(p=0.001)$. FeNO levels of the intermittent duration group $(n=36)$ and persistent duration group $(n=44)$ were $26.6 \pm 15.9$ and $41.2 \pm 24.4$ ppb, respectively, which were significantly different $(p=0.001)$.
\end{abstract}

Conclusion: FeNO levels were higher in children with increased severity and duration of AR. FeNO could be an indicator for classifying severity and evaluating treatment efficacy in children with AR.

Keywords: Allergic rhinitis; Nitric oxide; Biomarker; Monitoring; Children

\section{Introduction}

Allergic rhinitis (AR) is an IgE-mediated nasal inflammatory disorder which has one or more of nasal symptoms including rhinorrhea, sneezing, itching, and nasal obstruction [1]. The prevalence of AR has been increasing worldwide over the past $20 \mathrm{yrs}$ [2]. Some longitudinal studies provide evidence that allergic rhinitis can be developed in the first years of life and served as a significant risk factor for the development of asthma [3-5]. However, it is not easy to distinguish AR from other nasal diseases such as sinusitis or nonallergic rhinitis (NAR) in young children. In a study with a general population of Korean children, only about $50 \%$ of children who reported doctor diagnosed AR were proved to having AR by using questionnaire and skin test [6]. As AR not only causes symptomatic discomfort, but also reduces the quality of daily life, such as learning difficulties and sleep disturbances [7], early diagnosis and appropriate treatment are necessary in children. However, there have been few reliable biomarkers for evaluating severity as well as monitoring treatment response in children with allergic rhinitis.

Fractional exhaled nitric oxide (FeNO) is mainly used to diagnose atopic asthma, particularly as a biological marker for the evaluation of eosinophilic bronchial inflammation. Previous studies suggested that
FeNO could be used additionally as a diagnostic marker for AR in children $[8,9]$. FeNO can be easily measured in young children with adequate practice. However, it has not been well investigated that FeNO can predict AR severity in children [8].

Therefore, the objective of this study was to investigate whether FeNO could be used as an objective parameter for classifying AR severity in children.

\section{Materials and Methods}

\section{Study subjects}

Children who presented to the Department of Pediatrics at Inha University Hospital from 2015 to 2016 with nasal symptoms such as rhinorrhea, sneezing, nasal obstruction, and nasal itching were included for this study. However, children who had signs of acute infection within the past 3 weeks, took regular based anti-allergic medication, and had asthma symptoms within the past 3 months were excluded. AR was diagnosed in children with verified sensitization to any inhalant allergen in antigen-specific IgE tests. Children who had negative results on antigen-specific IgE tests were diagnosed with NAR. All subjects with asthma were in a stable state, without asthma symptoms for at least 2 months. This retrospective study was approved by the Institutional Review Board of Inha University Hospital (INHAUH 2016-11-022). 
Page 2 of 5

\section{Study methods}

A skin prick test was performed with positive control (1\% histamine), negative control (normal saline), and 27 allergens; house dust mites (HDM) (Dermatophagoides pteronyssinus, Dermatophagoides farinae), pollen (tree; Cryptomeria [Japanese cedar], Pinus [pine], Salix [willow], Acer [maple], Betula [birch], Quercus [oak], Alnus [alder], Ulmus [elm], weed; Ambrosia [ragweed], Artemisia [mugwort], Humulus [Japanese hop], Chenopodiaceae [fat hen], Plantago [plantain], grass; Cynodon [Bermuda grass], Phleum [timothy grass], Lolium [rye grass], Dactylis [orchard grass], Poa [meadow grass], Anthoxanthum [vernal grass]), mold (Penicillatum, Aspergillus, Cladosporium, and Alternaria) and pet (dog hair and cat fur) [10].

Pulmonary function test was conducted according to the guidelines of the American Thoracic Society/European Respiratory Society (ATS/ ERS) [11].

Nasal Index Score (NIS) was assessed; each of the 4 symptoms of nasal obstruction, rhinorrhea, sneezing, and nasal itching was subjectively assessed according to a grading scale from 0 to 3 (none $=0$; mild $=1$; obvious but tolerable $=2$; in-tolerable, affecting daily activities or sleep=3), with total scores ranging from 0 to 12 [12].

The AR patients were divided into the mild intermittent group, the mild persistent group, the moderate-to-severe intermittent group, and the moderate-to-severe persistent group based on the Allergic Rhinitis Impact on Asthma (ARIA) classification [1]. Then, the patients from 4 ARIA classes collapsed into the 2 groups based on severity or duration; the mild group and the moderate-to severe group, the intermittent group and the persistent group.

FeNO measurement was obtained using a NIOX MINO device (Aerocrine AB, Solna, Sweden) according to the ATS/ERS guidelines [13]. Briefly, patients were asked to avoid food intake or exercise within $1 \mathrm{~h}$ before the measurement, and the test was performed in the sitting position with a mouthpiece placed in the patient's mouth. After the patient inspired until total lung capacity was achieved, the FeNO level was recorded while the patient steadily exhaled with the target expiration flow of $50 \mathrm{ml} / \mathrm{s}$ until the velopharyngeal aperture was closed.

\section{Statistical analysis}

SAS ver.9.4 (SAS Institute Inc. Cornelius, NC, USA) was used for statistical analysis. Data were expressed as mean \pm standard deviation. The distribution of the data and homogeneity of variances was checked before applying parametric tests. The logarithmic value of FeNO was used to obtain an approximately normal distribution. Wilcoxon signed rank test were performed to compare FeNO levels between the AR group and the NAR group. To compare the differences between FeNO and NIS for each symptom type, a generalized linear model was performed, after adjusting for sex, age, and presence/absence of asthma. Additionally, a generalized linear model was used to evaluate differences in FeNO levels according to symptom severity and duration based on the ARIA classification.

A $p<0.05$ was considered to be statistically significant.

\section{Results}

\section{Characteristics of the study subjects}

Of a total of 107 patients, 80 had AR, including 46 males and 34 females (mean age, $10.1 \pm 2.7 \mathrm{yrs}$ ), and 27 had NAR, including 9 males and 18 females (mean age, $9.0 \pm 2.9 \mathrm{yrs}$ ). There was no significant difference in age, height, weight, or family history between the AR and NAR groups. The rate of asthma was higher in the AR group than in the NAR group $(28.8 \%$ vs. $11.1 \%$, respectively; $\mathrm{p}=0.010)$. The rate of past atopic dermatitis was also higher in the AR group than in the NAR group $(30.0 \%$ vs. $7.4 \%$, respectively; $\mathrm{p}=0.018)$. The serum $\operatorname{IgE}$ level was $476.4 \pm 352.6 \mathrm{IU} / \mathrm{ml}$ in the AR group, which was significantly higher than that of $71.1 \pm 68.9 \mathrm{IU} / \mathrm{ml}$ in the NAR group $(\mathrm{p}=0.001)$. FeNO levels in the AR and NAR groups were $34.7 \pm 22.1$ and $17.0 \pm$ $13.1 \mathrm{ppb}(\mathrm{p}=0.001)$. The PFTs showed that the predicted FEV1, predicted FVC, FEV1/FVC, and FEF $25-75 \%$ did not significantly differ between the 2 groups (Table 1 ).

\begin{tabular}{|c|c|c|c|}
\hline Characteristics & AR $(n=80)$ & NAR $(n=27)$ & $p$ value \\
\hline \multicolumn{4}{|l|}{ Sex } \\
\hline Male & 46 & 9 & \\
\hline Female & 34 & 18 & \\
\hline Age, $\mathrm{yr}^{*}$ & $10.1 \pm 2.7$ & $9.0 \pm 2.9$ & 0.082 \\
\hline Height, $\mathrm{cm}^{*}$ & $141.3 \pm 17.7$ & $134.8 \pm 16.7$ & 0.076 \\
\hline Weight, kg ${ }^{*}$ & $39.9 \pm 15.8$ & $33.6 \pm 14.2$ & 0.068 \\
\hline Familial history & & & 0.103 \\
\hline Yes & $39(48.8 \%)$ & $9(33.3 \%)$ & \\
\hline No & $41(51.2 \%)$ & $18(66.7 \%)$ & \\
\hline Past history of $\mathbf{A S}^{\dagger}$ & & & 0.01 \\
\hline Yes & $30(37.5 \%)$ & $3(11.1 \%)$ & \\
\hline No & $50(62.5 \%)$ & $24(88.9 \%)$ & \\
\hline Past history of $\mathrm{AD}^{\dagger}$ & & & 0.018 \\
\hline Yes & $24(30.0 \%)$ & $2(7.4 \%)$ & \\
\hline No & $56(70.0 \%)$ & $25(92.6 \%)$ & \\
\hline Serum IgE, IU/mL & $476.4 \pm 352.6$ & $71.1 \pm 68.9$ & 0.001 \\
\hline FeNO, $\mathrm{ppb}^{*}$ & $34.7 \pm 22.1$ & $17.0 \pm 13.1$ & \\
\hline FeNO, $\mathrm{ppb}^{* *}$ & $28.5[20.0-40.0]$ & $13.0[12.0-17.0]$ & 0.001 \\
\hline \multicolumn{4}{|c|}{ Pulmonary function test } \\
\hline FEV1, pred \% ${ }^{*}$ & $98.6 \pm 11.1$ & $97.8 \pm 11.7$ & 0.791 \\
\hline FVC, pred \%* & $97.3 \pm 12.9$ & $98.1 \pm 10.7$ & 0.817 \\
\hline FEV1/FVC \%* & $101.9 \pm 8.0$ & $100.1 \pm 7.8$ & 0.397 \\
\hline FEF $25-75 \%{ }^{*}$ & $87.3 \pm 19.7$ & $78.5 \pm 20.4$ & 0.11 \\
\hline
\end{tabular}

Table 1: General characteristics of subjects. 
There was no difference in FeNO between the AR patients with asthma and the AR patients without asthma ( $\mathrm{p}=0.778)$ (Table 2).

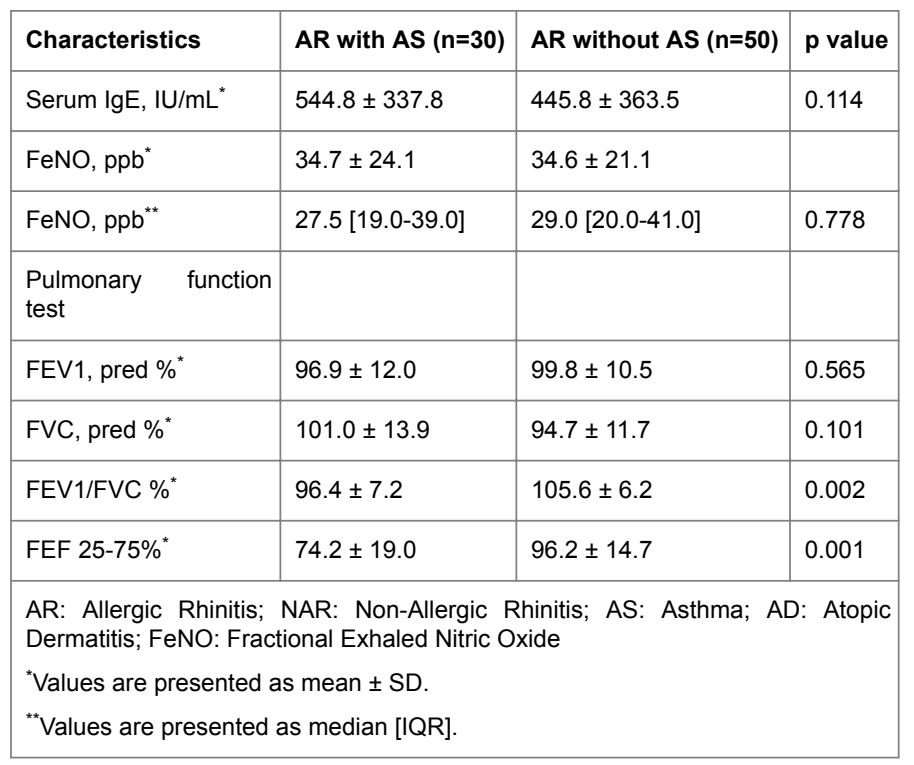

Table 2: Levels of IgE, FeNO, and spirometric parameters in the children with allergic rhinitis.

\section{NIS and FeNO}

In subjects with AR ( $\mathrm{n}=80)$, FeNO level was $33.9 \pm 22.0 \mathrm{ppb}$ in 73 patients with nasal obstruction, $35.2 \pm 21.7 \mathrm{ppb}$ in 67 patients with rhinorrhea, $30.6 \pm 17.2 \mathrm{ppb}$ in 48 patients with nasal itching, and 35.4 $\pm 23.8 \mathrm{ppb}$ in 61 patients with sneezing (Table 3 ).

\begin{tabular}{|c|c|c|c|}
\hline \multirow[t]{2}{*}{ Levels } & \multicolumn{2}{|l|}{ Symptom } & \multirow[b]{2}{*}{$p$ value } \\
\hline & Yes & No & \\
\hline \multicolumn{4}{|c|}{ Nasal obstruction } \\
\hline FeNO, ppb & $33.9 \pm 22.0$ & $42.1 \pm 23.2$ & \\
\hline Log FeNO & $3.4 \pm 0.6$ & $3.6 \pm 0.6$ & 0.256 \\
\hline \multicolumn{4}{|l|}{ Rhinorrhea } \\
\hline FeNO, ppb & $35.2 \pm 21.7$ & $32.0 \pm 24.8$ & \\
\hline Log FeNO & $3.4 \pm 0.6$ & $3.3 \pm 0.6$ & 0.560 \\
\hline \multicolumn{4}{|c|}{ Nasal itching } \\
\hline FeNO, ppb & $30.6 \pm 17.2$ & $40.7 \pm 27.1$ & \\
\hline Log FeNO & $3.3 \pm 0.5$ & $3.5 \pm 0.6$ & 0.169 \\
\hline \multicolumn{4}{|l|}{ Sneezing } \\
\hline FeNO, ppb & $35.4 \pm 23.8$ & $32.3 \pm 15.9$ & \\
\hline Log FeNO & $3.4 \pm 0.6$ & $3.3 \pm 0.5$ & 0.893 \\
\hline \multicolumn{4}{|c|}{ FeNO, fractional exhaled nitric oxide } \\
\hline
\end{tabular}

The analyses were adjusted for age, sex, mother's educational level, and maternal smoking during pregnancy.

Table 3: FeNO levels according to allergic rhinitis symptom.

\begin{tabular}{|l|l|l|l|}
\hline & \multicolumn{2}{|l|}{ Number of symptoms } & p value \\
\hline & 1 or $2(\mathrm{n}=21)$ & $\geq 3(\mathrm{n}=59)$ & \\
\hline FeNO, ppb & $37.8 \pm 24.7$ & $33.5 \pm 21.2$ & \\
\hline & $33.0(26.0-45.0)$ & $28.0(20.0-38.0)$ & 0.529 \\
\hline FeNO, fractional exhaled nitric oxide & \\
\hline \multicolumn{2}{|l}{ Values are presented as mean \pm SD/median (IQR) } \\
\hline
\end{tabular}

Table 4: FeNO levels according to number of allergic rhinitis symptoms.

The FeNO level of patients with 1 or 2 symptoms ( $n=21)$ was $37.8 \pm$ $24.7 \mathrm{ppb}$, whereas the FeNO level of patients with $\geq 3$ symptoms $(\mathrm{n}=59)$ was $33.5 \pm 21.2 \mathrm{ppb}$, which did not significantly differ $(\mathrm{p}=0.529)$ (Table 4).

There was no significant difference in FeNO level according to the NIS score for nasal obstruction (parameter estimates $=-0.224, \mathrm{p}=0.308$ ), rhinorrhea (parameter estimates $=0.092, \mathrm{p}=00.589$ ), nasal itching (parameter estimates $=-0.146, \mathrm{p}=0.283$ ), or sneezing (parameter estimates $=-0.031, \mathrm{p}=0.833)$. There was no correlation between FeNO and total NIS score $(\mathrm{p}=0.943)$.

\section{Association between AR severity and FeNO}

When the FeNO levels were assessed according to AR severity based on the ARIA classification, FeNO levels were $14.3 \pm 3.7 \mathrm{ppb}$ in the mild intermittent group $(\mathrm{n}=11), 22.7 \pm 4.8 \mathrm{ppb}$ in the mild persistent group $(\mathrm{n}=12), 32.1 \pm 16.1 \mathrm{ppb}$ in the moderate-to-severe intermittent group $(\mathrm{n}=25)$, and $48.2 \pm 25.2 \mathrm{ppb}$ in the moderate-to-severe persistent group $(\mathrm{n}=32)$. The FeNO level was significantly higher in the moderate-tosevere persistent group than in the mild persistent group $(p=0.001)$ and in the moderate-to-severe intermittent group $(\mathrm{p}=0.005)$. Furthermore, FeNO was significantly higher in the moderate-to-severe intermittent group than in the mild intermittent group $(\mathrm{p}=0.001)$. The FeNO level of the mild persistent group was higher than that of the mild intermittent group ( $\mathrm{p}=0.053$ ) (Figure 1).

For AR symptom severity, FeNO levels significantly differed between the mild symptom group $(\mathrm{n}=23,18.7 \pm 6.0 \mathrm{ppb})$ and the moderate-to-severe symptom group $(n=57,41.1 \pm 23.0 \mathrm{ppb} ; \mathrm{p}=0.001)$; a generalized linear model indicated an F-value of 14.05. For AR symptom duration, FeNO levels significantly differed between the intermittent duration group $(\mathrm{n}=36,26.6 \pm 15.9 \mathrm{ppb})$ and the persistent duration group $(n=44,41.2 \pm 24.4 \mathrm{ppb} ; \mathrm{p}=0.001)$; a generalized linear model indicated an F-value of 6.45 (Figure 2).

\section{Discussion}

In the present study, FeNO levels were measured to determine its potential to evaluate symptom severity and duration in children with AR. This study shows interesting findings. The FeNO level in the moderate-to-severe symptom group was significantly higher than that in the mild symptom group. In addition, FeNO level was significantly 
higher in the persistent duration group than that in the intermittent duration group, which were consistent with an adult study [14].

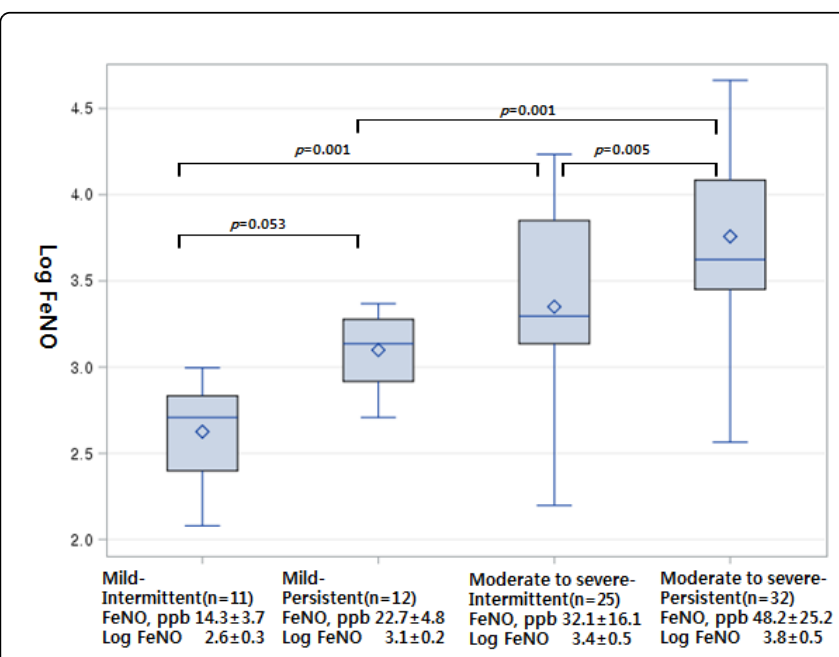

Figure 1: FeNO levels (ppb) of the mild intermittent group, mild persistent group, moderate-to-severe intermittent group, and moderate-to severe persistent group according to ARIA classification. Values are presented as mean \pm standard deviation. FeNO, fractional exhaled nitric oxide.

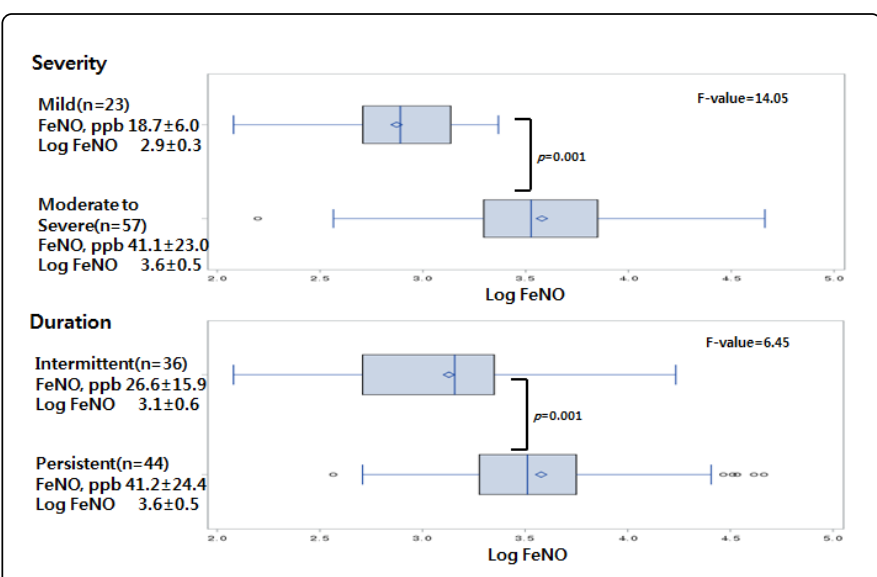

Figure 2: FeNO levels according to symptom severity (mild vs. moderate-to-severe) and duration (intermittent vs. persistent), and F-values of the 2 factors (severity and duration) with FeNO levels determined by generalized linear model. Values are presented as mean \pm standard deviation. FeNO, fractional exhaled nitric oxide.

This study results suggest that FeNO level increases with an increase in severity and duration of AR. In the generalized linear model of FeNO level with severity and duration, the F-value for severity was 14.05 , which was higher than that of 6.45 for duration, thus indicating that severity is a more dominant factor than duration in determining FeNO level.

In this study, we determined the NIS by scoring the degree of the major AR symptoms felt by patients, including nasal obstruction, watery rhinorrhea, sneezing, and nasal itching, from 0 to 3 points. There were no differences in FeNO levels according to the type of symptoms present. In addition, FeNO level did not increase with an increase in the number of symptoms. There were no significant differences between FeNO levels and the symptom scores of each symptom, and there was no correlation between FeNO level and total NIS score. In contrast to our study, a study with adults found weak correlations between FeNO levels and the symptoms scores of watery rhinorrhea, sneezing, and total symptoms [15]. The classification of the severity of rhinitis can be carried out using simple assessment of visual analog scale [15]. However, there are few studies evaluating the association between degree of subjective symptoms and disease severity in children with AR. We measured the score of children's subjective symptoms, not objective measurements. Therefore, we assume that the degree of symptoms experienced by children does not reflect AR severity. Thus, treatment response could be monitored by objective parameters, not by degree of subjective symptoms in children with AR.

The increased FeNO in patients with AR might reflect inflammation of lower airway, a feature in the concept of one airway disease [16]. It was reported that diffusing capacity of $\mathrm{NO}$ in the bronchial wall of patients with AR was high, suggesting subclinical change of bronchial mucosa in AR [17]. The nasal nitric oxide levels were found to decrease in children with AR after topical corticosteroids were administered [18]. This finding is reportedly related to the inhibition of inducible nitric oxide synthase by the steroid [19] and is also observed in adults [20].

Because of small samples, children with both AR and asthma were included for statistical power in this study. FeNO levels could be reflected by asthma component. However, all children with asthma were in stable state without regular based medication. There was no difference in spirometry parameters between the AR and NAR groups. In addition, there was no difference in FeNO between the AR patients with asthma and those without asthma. The analyses were adjusted for asthma. Thus, from our study results of increased FeNO levels in the more severe AR groups, we suggest that FeNO level could be useful indicator for monitoring of AR treatment.

In conclusion, FeNO level increased with an increase in severity and duration of $\mathrm{AR}$ and was more reflective of symptom severity than symptom duration. Based on these results, we suggest that FeNO measurement might be useful indicator for the evaluation of AR severity in children. In addition, FeNO level could be a better indicator than subjective nasal symptom score for evaluation of treatment response in children with AR.

\section{Acknowledgements}

The authors have no actual or potential competing financial and private interests that might be perceived as influencing the results or interpretation of this study, which was performed with funding from the Ministry of Environment.

\section{References}

1. Bousquet J, Khaltaev N, Cruz AA, Denburq J, Fokkens WJ, et al. (2008) Allergic Rhinitis and its Impact on Asthma (ARIA) 2008 update (in collaboration with the World Health Organization, GA(2)LEN and AllerGen). Allergy 63: 8-160.

2. Jee HM, Kim KW, Kim CS, Sohn MH, Shin DC, et al. (2009) Prevalence of Asthma, Rhinitis and Eczema in Korean Children Using the International Study of Asthma and Allergies in Childhood (ISAAC) Questionnaires. Pediatr Allergy Respir Dis 19: 165-172. 
Citation: Kim JH, Park JS, Moon SH, Lim DH, Hwang SY, et al. (2017) Exhaled Nitric Oxide and Symptom Severity in Children with Allergic

3. Peroni DG, Piacentini GL, Alfonsi L, Zerman L, Di Blasi P, et al. (2003) Rhinitis in pre-school children: prevalence, association with allergic diseases and risk factors. Clin Exp Allergy 33: 1349-1354.

4. Settipane RJ, Hagy GW, Settipane GA (1994) Long-term risk factors for developing asthma and allergic rhinitis: a 23-year follow-up study of college students. Allergy Proc 15: 21-25.

5. Porsbjerg C, Von Linstow ML, Ulrik CS, Nepper-Christensen S, Backer V (2006) Risk factors for onset of asthma: a 12-year prospective follow-up study. Chest 129: 309-316.

6. Kim DH, Park YS, Jang HJ, Kim JH, Lim DH (2016) Prevalence and allergen of allergic rhinitis in Korean children. Am J Rhinol Allergy 30: e72-e78.

7. Tripathi A, Patterson R (2001) Impact of allergic rhinitis treatment on quality of life. Pharmacoeconomics 19: 891-899.

8. Moon SH, Jang HJ, Park YS, Lee WY, Lim DH, et al. (2015) Fractional exhaled nitric oxide in Korean children with allergic rhinitis. Allergy Asthma Respir Dis 3: 439-445.

9. Kim YH, Park HB, Kim MJ, Kim HS, Lee HS, et al. (2014) Fractional exhaled nitric oxide and impulse oscillometry in children with allergic rhinitis. Allergy Asthma Immunnol Res 6: 27-32.

10. Son BK, Lim DH (2007) Allergic skin test. Korean J Pediatr 50: 409-415.

11. Miller MR, Hankinson J, Brusasco V, Burgos F, Casabury R, et al. (2005) Standardisation of spirometry. Eur Respir J 26: 319-338.

12. Kim JH, Ahn YM, Kim HJ, Lim DH, Son BK, et al. (2014) Development of a questionnaire for the assessment of quality of life in Korean children with allergic rhinitis. Allergy Asthma Immunol Res 6: 541-547.
13. American Thoracic Society; European Respiratory Society (2005) ATS/ERS recommendations for standardized procedures for the online and offline measurement of exhaled lower respiratory nitric oxide and nasal nitric oxide, 2005. Am J Respir Crit Care Med 171: 912-930.

14. Lee KJ, Cho SH, Lee SH, Tae K, Yoon HJ, et al. (2012) Nasal and exhaled nitric oxide in allergic rhinitis. Clin Exp Otorhinolaryngol 5: 228-233.

15. Bousquet PJ, Combescure C, Neukirch F, Klossek JM, Mechin H, et al. (2007) Visual analog scales can assess the severity of rhinitis graded according to ARIA guidelines. Allergy 62: 367-372.

16. Smith L (1998) Special considerations for the child with airway disease. J Allergy Clin Immunol 101: 370-372.

17. Kim HB, Eckel SP, Kim JH, Gilliland FD (2016) Exhaled NO: determinants and clinical application in children with allergic airway disease. Allergy Asthma Immunol Res 8: 12-21.

18. Baraldi E, Azzolin NM, Carra S, Dario C, Marchesini F, et al. (1998) Effect of topical steroids on nasal nitric oxide production in children with perennial allergic rhinitis: a pilot study. Respir Med 92: 558-561.

19. Gaston B, Drazen JM, Loscalzo J, Stamler JS (1994) The biology of nitrogen oxides in the airways. Am J Respir Crit Care Med 149: 538-551.

20. Kharitonov SA, Rajakulasingam K, O’Connor B, Durham SR, Barnes PJ (1997) Nasal nitric oxide is increased in patients with asthma and allergic rhinitis and may be modulated by nasal glucocorticoids. J Allergy Clin Immunology 99: 58-64. 